\title{
Deciphering Preferred Geometries of Pyridylmethylamines- Based Complexes: A Robust Strategy Combining NMR, DFT and X-Ray
}

Benjamin Large ${ }^{a}$, Maissa Meddeb ${ }^{b}$, José Enrique Herbert Pucheta ${ }^{b, c}$, Anne Gaucher ${ }^{a}$, Marie Cordier $^{\mathrm{d}}$, Corinne Gosminid ${ }^{\mathrm{d}}$, Jonathan Farjon ${ }^{\star, b, e}$, Audrey Auffrant ${ }^{\star, d}$, Damien Prim ${ }^{\star, a}$

\footnotetext{
a Institut Lavoisier de Versailles, UVSQ, CNRS, Université Paris-Saclay, 78035 Versailles, France. Email:Damien.prim@uvsq.fr

b Institut de Chimie Moléculaire et des Matériaux d'Orsay, University of Paris-Sud, UMR 8182, 91405 Orsay, France

- Consejo Nacional de Ciencia y Tecnología - Laboratorio Nacional de Investigación y Servicio Agroalimentario y Forestal, Universidad Autónoma Chapingo, Km 38.5 Carretera México - Texcoco, Chapingo 56230, Estado de México, México

d Laboratoire de Chimie Moléculaire, CNRS, École Polytechnique, IP Paris, 91128 Palaiseau, France. E-mail: audrey.auffrant@polytechnique.edu

e CEISAM UMR-CNRS 6230, Faculté des Sciences et Techniques, 2 Rue de la Houssinière, BP 92208, 6230 Nantes, France. E-mail: jonathan.farjon@univ-nantes.fr
}

Abstract: The preparation of pyridylmethylamines (pma)- $\mathrm{ZnBr}_{2}$ and $-\mathrm{CoBr}_{2}$ complexes is described. Accurate structural informations in both solution and solid state have been obtained using an approach combining advanced NMR such as pure shift gradient-encoded selective refocusing (PS-GSERF) and conventional NOESY experiments, DFT calculations and X-ray analysis. The methodology developed has allowed a clear identification and characterization of preferred conformations and configurations at an atomic resolution. Our study has evidenced some key features of the overall 3D structure of pma-Zn and pma-Co complexes which shapes are set by the geometry of the metallacycle, the configuration of the $\mathrm{sp}^{3}$ nitrogen atom, the equatorial position of the benzyl side arm as well as the preferred spatial arrangement of the chiral side arm with respect to the metallacycle.

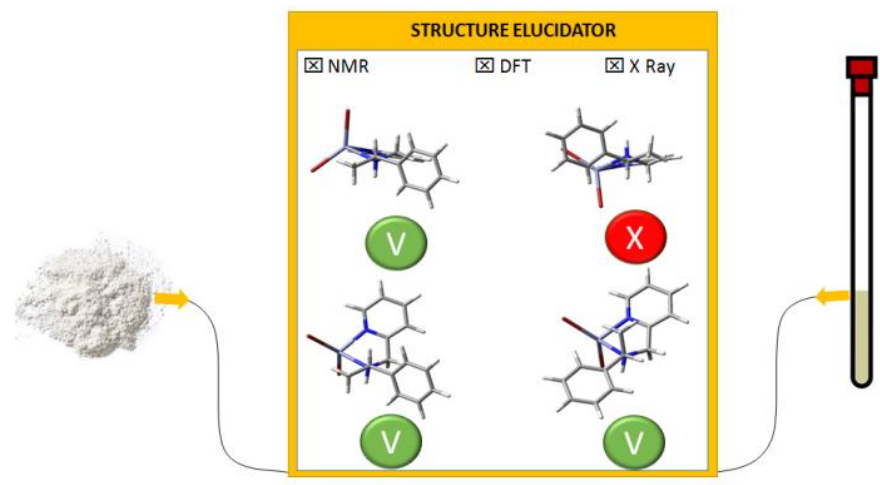

Keywords : pyridylmethylamine, Zn, Co, complexation, X-Ray

\section{Introduction}


Over the last two decades, complexation properties of pyridylmethylamines (pma) and their derivatives to various transition metals have attracted continuous interest for a broad scientific community. ${ }^{1-10}$ The pma scaffold comprises a pyridine ring substituted by a methylamine pendant arm and belongs to the general $1,2-N, N$ bidentate ligands family. Those pma ligands display two distinct nitrogen atoms: the $N$-heterocyclic and the $\mathrm{sp}^{3}$ nitrogen atoms. The growing popularity of pma ligands arise by part from their facile synthesis. Advantageously, their electronic and steric properties can be customized by the easy installation of various substituents at the pyridine ring, the methylene carbon atom and the $\mathrm{sp}^{3}$ nitrogen atom (Figure 1). This ligand modularity enables pma to complex metals such as $\mathrm{Cu}, \mathrm{Re}, \mathrm{Fe}, \mathrm{Pd}, \mathrm{Pt}, \mathrm{Mg}, \mathrm{Ti}, \mathrm{Ni}$ or $\mathrm{Yb}$. Moreover, its ability to generate pma- $\mathrm{H}^{+}$complexes has also been recently demonstrated. ${ }^{11}$ Such compounds revealed especially valuable as catalytic systems in various synthetic organo- and metallo-promoted transformations including oxidative $\mathrm{C}-\mathrm{C}$ bond formation, cycloaddition reactions, Friedel-Crafts alkylation, Henry reaction, Suzuki coupling, $\mathrm{C}-\mathrm{H}$ arylation. ${ }^{11-25}$

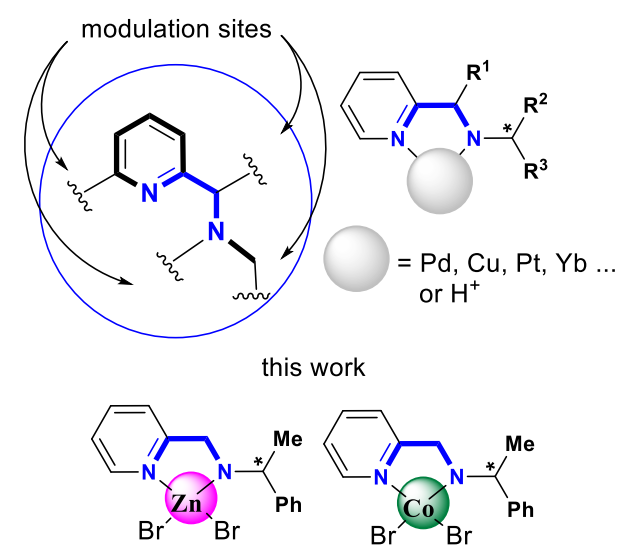

Figure 1. Pma modulation sites, transition metal and proton complexes and $\mathrm{Zn}^{\prime \prime}$ and $\mathrm{Co}^{\prime \prime}$ complexes.

Among the various transition metal complexes, pma- $Z n^{\|}$association focused emerging attention in several areas. Indeed, pma-Zn complexes were found efficient as enantiomeric excess determination tool $\mathrm{l}^{26-27}$ and in the polymerization of rac-lactide. ${ }^{28-29}$

In addition, as a consequence of the crucial role played by $\mathrm{Zn}^{\|}$ions in several biological processes and diseases associated with the variation of its concentration, ${ }^{30-36}$ pma-based platforms have been used as model ligands in molecular recognition, fluorescent probes and imaging agent. ${ }^{1,37-42}$ In this context, both the coordination mode and the geometry of pma$\mathrm{Zn}$ " complexes are key elements to study in order to fully understand and/ or predict their behaviour and reactivity. Indeed, tiny modifications of the coordination sphere are known to 
affect the reactivity of $\mathrm{Zn}$ species within the active sites of $\mathrm{Zn}$-containing enzymes, deeply impact catalytic activities and induce conformational modifications. ${ }^{43-45}$ While the preparation of pma- $\mathrm{ZnCl}_{2}$ complexes and the description of their properties accompanied by solid state data were disclosed in a few reports, ${ }^{28,37}$ the pma- $\mathrm{ZnBr}_{2}$ complexes are more scarcely described. ${ }^{46,47}$ In this communication we focused on the preparation of pma- $\mathrm{ZnBr}_{2}$ complexes based on $\mathrm{N}, \mathrm{N}$-bidentate ligands. In order to gain accurate structural information in both solution and solid state, we describe herein the first issue of an approach combining DFT calculations and advanced NMR such as pure shift gradient-encoded selective refocusing (PS-GSERF) and standard NOESY experiments towards well-defined neutral $\mathrm{Zn}^{\prime \prime}$ complexes. This methodology has allowed clear identification and characterization of preferred geometries at an atomic resolution. Based on the $\mathrm{Zn}$ complexes model, we also describe the preparation of unprecedented Co complexes from the same ligand family. Indeed, Co exhibits a comparable coordination sphere to $\mathrm{Zn}$, is a cheap metal that have found ongoing developments in catalysis for example..$^{48-52}$ In this context, gaining a first set of structural information is undoubtedly of broad interest. The geometry of Co complexes is analyzed from solid-state data and finally compared to their $\mathrm{Zn}$ analogues.

\section{Results and discussion}

\subsection{Complex synthesis}

Ligands $\mathbf{L}^{\boldsymbol{S}}$ and $\mathbf{L}^{\boldsymbol{R}}$ were first prepared according to classical techniques, ${ }^{20,53-55}$ starting from commercially available pyridin-2-carboxaldehyde and the corresponding benzylic amine in the presence of $\mathrm{MgSO}_{4}$. The imine intermediate which is quantitatively formed after $2 \mathrm{~h}$ stirring at room temperature is reduced with $\mathrm{NaBH}_{4}$ in $\mathrm{MeOH}$ affording the target pma ligands in quantitative yields (Scheme 1).

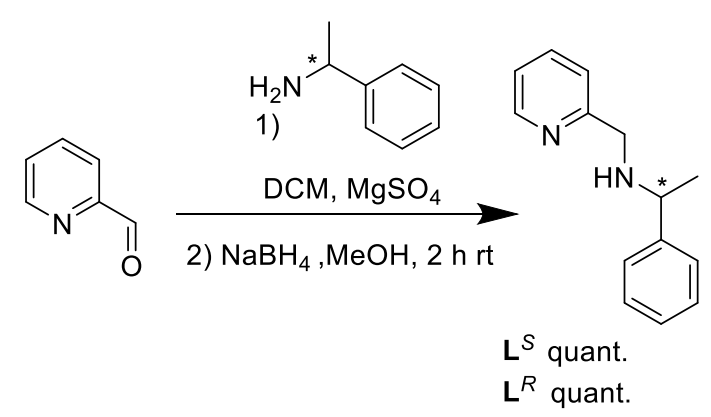

Scheme 1. Preparation of ligands $L^{S}$ and $L^{R}$.

Complexation of ligands $\mathbf{L}^{s}$ and $\mathbf{L}^{\boldsymbol{R}}$ to $\mathrm{ZnBr}_{2}$ was next examined. Both ligands were independently reacted with anhydrous $\mathrm{ZnBr}_{2}$ in distilled THF. The clear reaction mixture was 
stirred for $16 \mathrm{~h}$ at room temperature. In contrast to other pma-metal complexes which spontaneously precipitated, ${ }^{20}$ complexes 1 and 2 remained soluble and their isolation required solvent evaporation and several washes with $\mathrm{Et}_{2} \mathrm{O}$. Both complexes were isolated as white solids in 58 and $79 \%$ yield. Both ${ }^{1} \mathrm{H}$ and ${ }^{13} \mathrm{C}$ NMR spectra of complexes 1 and 2 display identical characteristic chemical shifts. As confirmed by solid state data (vide infra), $\mathbf{L}^{\boldsymbol{S}}$ and $\mathbf{L}^{\boldsymbol{R}}$ undergo a complexation process leading to two independent enantiomers $\mathbf{1}$ and $\mathbf{2}$ respectively. Similarly, pma-CoBr 2 complexes 3 and 4 could be isolated in 70 and $77 \%$ yield from ligands $\mathrm{CoBr}_{2}$ and $\mathbf{L}^{s}$ and $\mathbf{L}^{\boldsymbol{R}}$ respectively in freshly distilled THF.

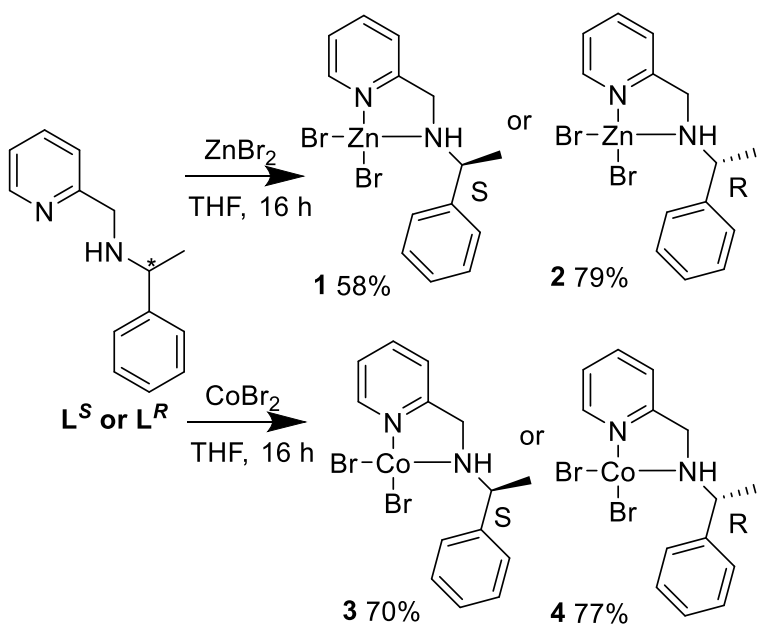

Scheme 1. Preparation of complexes 1-4.

\subsection{NMR as a probe to decipher the complex geometries}

During the complexation process several complexes might be obtained arising from two possible configurations of the nitrogen neo stereocenter and the two relative positions of the pendant nitrogen arm (equatorial or axial) of the metallacycle. The J-resolved technique, which is well-known to extract $\mathrm{J}_{\mathrm{H}, \mathrm{H}}$ couplings as a source of structural information, such as conformational preferences, has been applied to complex $1\left(\mathrm{~L}^{\mathrm{s}} \mathrm{ZnBr}_{2}\right)$. However, this method was limited since all $\mathrm{J}_{\mathrm{H}, \mathrm{H}}$ evolve at the same time rendering spectra difficult to interpret. Among NMR tools, the GSERF sequence is recognized as an original tool for simplifying the analysis of $\mathrm{J}_{\mathrm{H}, \mathrm{H}}$ couplings. ${ }^{56}$ Thus, different 2D GSERF maps have been recorded for $\mathbf{1}$ as well as some pure-shift versions allowing an enhancement of the spectral resolution along the direct dimension. ${ }^{58-59}$ 


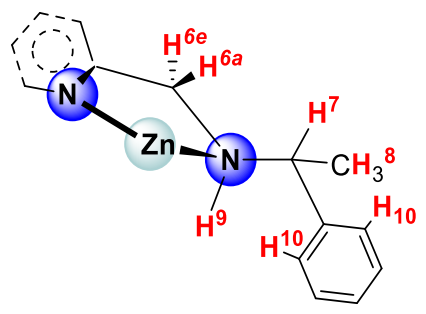

Figure 2. Numbering system adopted for protons of interest according to solid and liquid state data (vide infra).

By selecting different nuclei couple among which the nitrogen proton $\left(\mathrm{H}^{9}\right)$, the pseudo benzylic methylene protons $\left(\mathrm{H}^{6 \mathrm{a}}\right.$ axial and $\mathrm{H}^{6 \mathrm{e}}$ equatorial), and the pendant arm proton $\left(\mathrm{H}^{7}\right)$ as shown in Figure 2, it was easy to extract $J_{H 9, H 6}$ and $J_{H 9, H 7}$ respectively (see Figure 3). The latter $J_{H, H}$ are key data directly linked to the complex geometry through the well-known Karplus curve. Thus, ${ }^{3} \mathrm{~J}_{\mathrm{H} 9, \mathrm{H} 7}=12.5 \mathrm{~Hz}$ corresponds to a dihedral angle close to $180^{\circ}$ (see Figure 3 and DFT calculations vide infra). It has been more difficult to accurately measure ${ }^{3} \mathrm{~J}_{\mathrm{H} 9 \mathrm{H} 6}$ with GSERF experiment (see Figure $3 \mathrm{C}$ ) due to the strong coupling between the pseudo benzylic protons $\mathrm{H}^{6}$. In fact, $\mathrm{H}^{6 \mathrm{e}} / \mathrm{H}^{6 \mathrm{a}}$ remains a second order system whatever the temperature from 193 to $323 \mathrm{~K}$. To push over such a limit, the pure-shift GSERF allows easily measuring an averaged coupling for these two benzylic ${ }^{1} \mathrm{H}: \mathrm{J}_{\mathrm{H} 9, \mathrm{H} 6}=7.5 \mathrm{~Hz}$ thanks to the vanishing of $\mathrm{J}_{\mathrm{H}, \mathrm{H}}$ leading to improved spectral resolution by reducing the linewidth by 3 (Figure 3D). The latter corresponds to a dihedral angle $\mathrm{H}^{9}-\mathrm{N}-\mathrm{C}-\mathrm{H}^{6 \mathrm{a}}$ close to $180^{\circ}$ and therefore close to $90^{\circ}$ for $\mathrm{H}^{9}-\mathrm{N}-\mathrm{C}-\mathrm{H}^{6 e}$. These results confirm the most stable conformation of the metallacycle envelop leading to the equatorial position of the pendant arm nitrogen substituent.

To better understand the impact of different parameters on the overall geometry of the zinc complex, such as the configuration of the nitrogen stereocenter, the equatorial or axial position of the pendant arm nitrogen substituent and its spatial arrangement relative to $\mathrm{H}^{9}$, DFT calculations were carried out. 

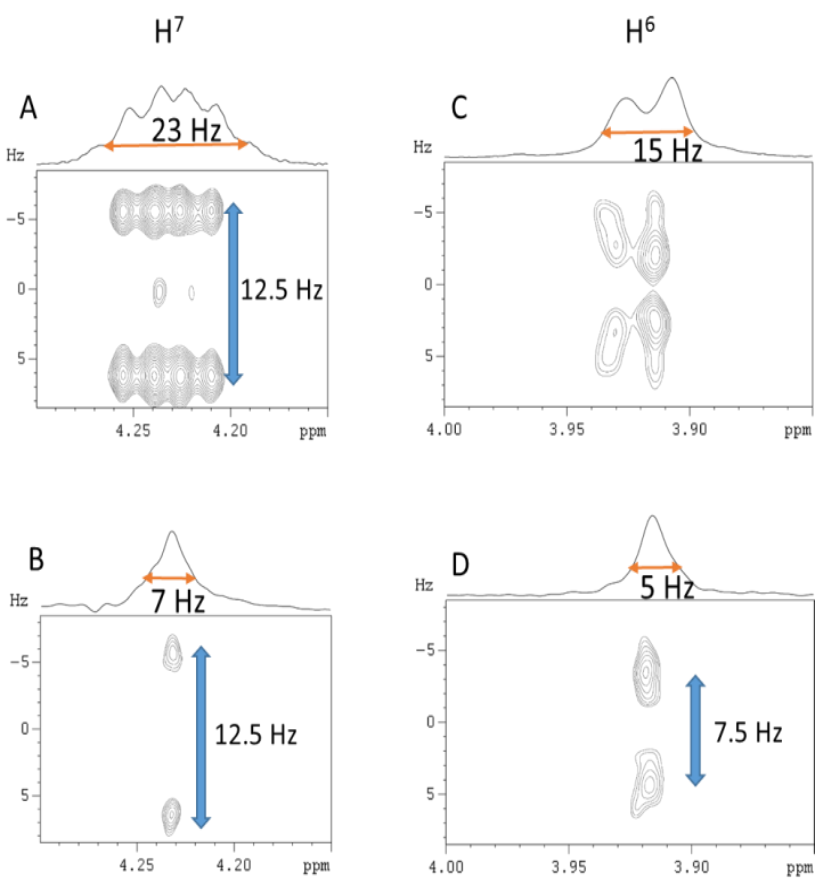

Figure 3. GSERF spectra (A, C) and pure-shift GSERF (B,D) on complex 1 at $193 \mathrm{~K}$ (see ESI). ${ }^{57}$ In spectra $A$ and $B, H^{7}$ is excited and $\mathrm{H}^{7}+\mathrm{H}^{9}$ are selected for measuring $\mathrm{J}_{\mathrm{H} 9, \mathrm{H}}$; In spectra $\mathrm{C}$ and $\mathrm{D}, \mathrm{H}^{6}$ are excited and $\mathrm{H}^{6}+\mathrm{H}^{9}$ are selected for measuring $\mathrm{J}_{\mathrm{H} 9, \mathrm{H} 6 \text {. }}$

\subsection{DFT calculations}

The structures of ligand $\mathbf{L}^{\boldsymbol{s}}$ and its corresponding complexes $\mathbf{1}$ have been optimized with the B3LYP/GEN 6-311G(d,p) (H,C,N) LANL2DZ ( $\mathrm{n}, \mathrm{Br}$ )/DFT level of theory (full details are given in the ESI). ${ }^{60}$ Four possible combinations labelled $1 \mathrm{eqN}^{S}$ (equatorial position of the pendant arm and $S$ configuration of the nitrogen atom), 1 eqN $N^{R}, 1 a x N^{S}$ and $1 a x N^{R}$ may arise from complexation. As shown in Figure $4,1 \mathrm{eqN}^{S}$ is the preferred spatial arrangement of the pendant arm nitrogen substituent over the corresponding $1 \operatorname{axN}^{S}, 1$ eq $\mathrm{N}^{R}$ and $\operatorname{1axN^{R}}$ structures by $1.1,5.9$ and $10.2 \mathrm{~kJ} / \mathrm{mol}$. Interestingly, inversion of the nitrogen configuration from $S$ to $R$ led to a clear discrimination of both potential equatorial complexes. $1 e^{-q} N^{S}$ is favoured by $10.2 \mathrm{~kJ} \mathrm{~mol}^{-1}$ over the $1 \mathrm{eqN}^{R}$ isomer. In accordance with NMR data, computed data imply that coordination of $\mathbf{L}^{s}$ affords $1 \mathrm{eqN}^{S}$ as the preferred isomer of four possible combinations. 


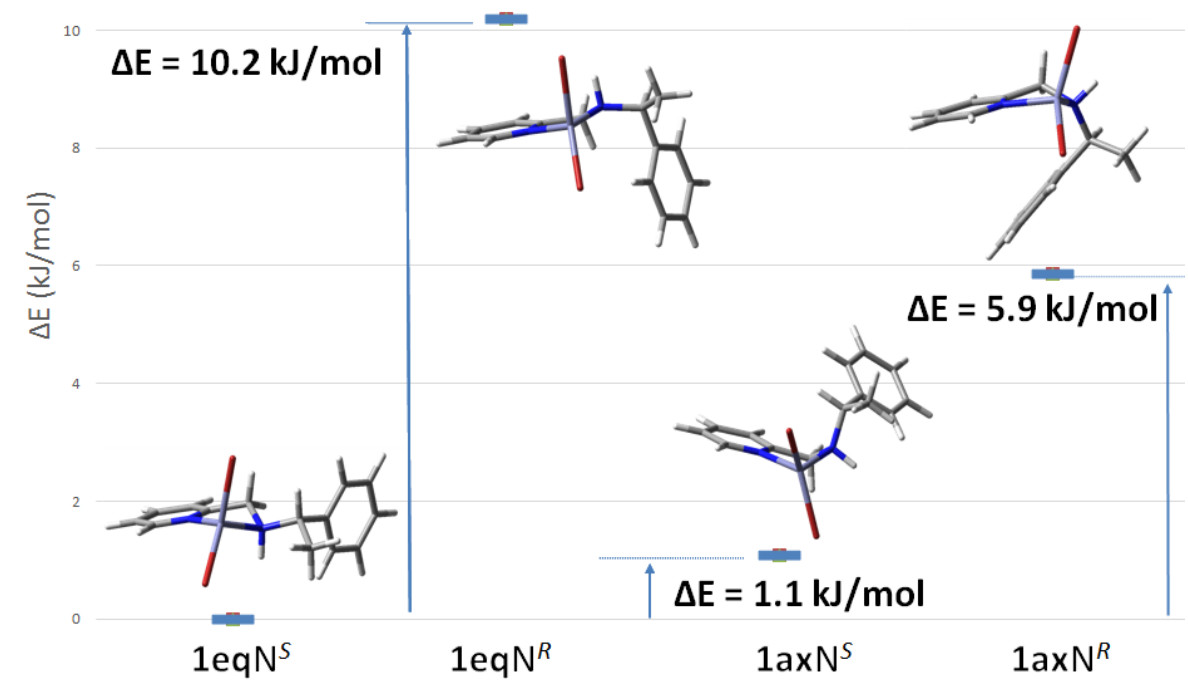

Figure 4. Comparison of computed potential geometries for complex $1\left(\mathrm{~L}^{\mathrm{S}} \mathrm{ZnBr} 2\right)$ with relative energies as compared to the most stable complex

In addition, as shown by the aforementioned NMR study, the conformation of the pendant nitrogen arm relative to $\mathrm{H}^{9}$ is of crucial importance and has also to be considered. Thus, we next examined the preferred spatial arrangement of the benzylic side arm with respect to the metallacycle in the most stable $1 \mathrm{eqN}^{S}$ isomer. To this end, possible conformations of the equatorial benzylic substituent have been computed by mean of an iterative change of the $\mathrm{H}^{9}-\mathrm{N}-\mathrm{C}-\mathrm{H}^{7}$ dihedral angle by $10^{\circ}$ (for full details see ESI, Figure S7). The less constrained conformer displays an anti-conformation of $\mathrm{H}^{7}$ and $\mathrm{H}^{9}$ hydrogen atoms characterized by a dihedral angle of $174^{\circ}$ as shown in Figure 5. All other potential conformations display higher energies ranging from 13.2 to $43.1 \mathrm{~kJ} . \mathrm{mol}^{-1}$.
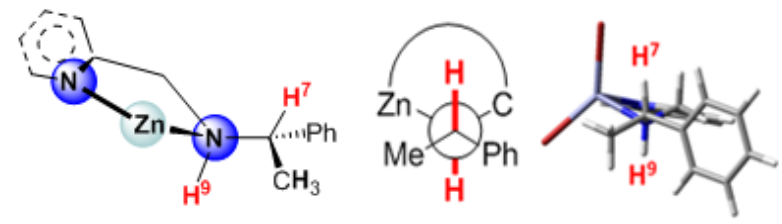

Figure 5. Computed preferred conformation of the equatorial benzylic substituent for complex 1.

This computed analysis confirms the selective complexation of ligand $\mathbf{L}^{s}$ and the formation of complex $1\left(\mathrm{~L}^{\mathrm{S}} \mathrm{ZnBr}_{2}\right)$ as the preferred geometry which architecture is set by the combination of three key features including (i) the $S$ configuration of the $\mathrm{sp}^{3}$ nitrogen atom, (ii) the equatorial position of the benzyl side arm and (iii) the preferred conformation of the benzylic 
substituent. These results are further supported by the solid-state structure analysis (vide infra).

In order to rationalize DFT structures in comparison to NMR data, interatomic short and long distances as well as $\mathrm{J}_{\mathrm{H}, \mathrm{H}}$ couplings have been considered.

\subsection{Comparison of NMR and DFT data.}

The calculation of $\mathrm{J}_{\mathrm{H}, \mathrm{H}}$ for 1 has to take into account the structures of lowest energy. If 1 eqN $\mathrm{N}^{S}$ is the preferred geometry, $1 \mathrm{eqN}^{S}$ and $1 \mathrm{axN}^{S}$ exhibit close computed energies and thus both have to be taken into consideration. As the input or calculation of the weight of each structure is given by the Boltzmann distribution, other analogues arising from $1 \mathrm{eqN}^{R}$ and $1 \operatorname{axN}^{R}$ might also contribute if their computed energies are comparable with those of $1 \mathrm{eqN}^{S}$ and $1 \operatorname{axN}^{S}$.

We thus compute all possible conformations for 1 eq $N^{R}, 1 a x N^{R}, 1 e q N^{S}$ and $1 a x N^{S}$ by mean of an iterative incrementation of the corresponding $\mathrm{H}^{9}-\mathrm{N}-\mathrm{C}-\mathrm{H}^{7}$ dihedral angle by $10^{\circ}$ in order to identify the conformers of lowest energy for all combinations (for full details see ESI). ${ }^{60}$ 
Table 1. Probabilities and calculated $\mathrm{J}_{\mathrm{H}, \mathrm{H}}$ for lowest energy conformers of complex 1

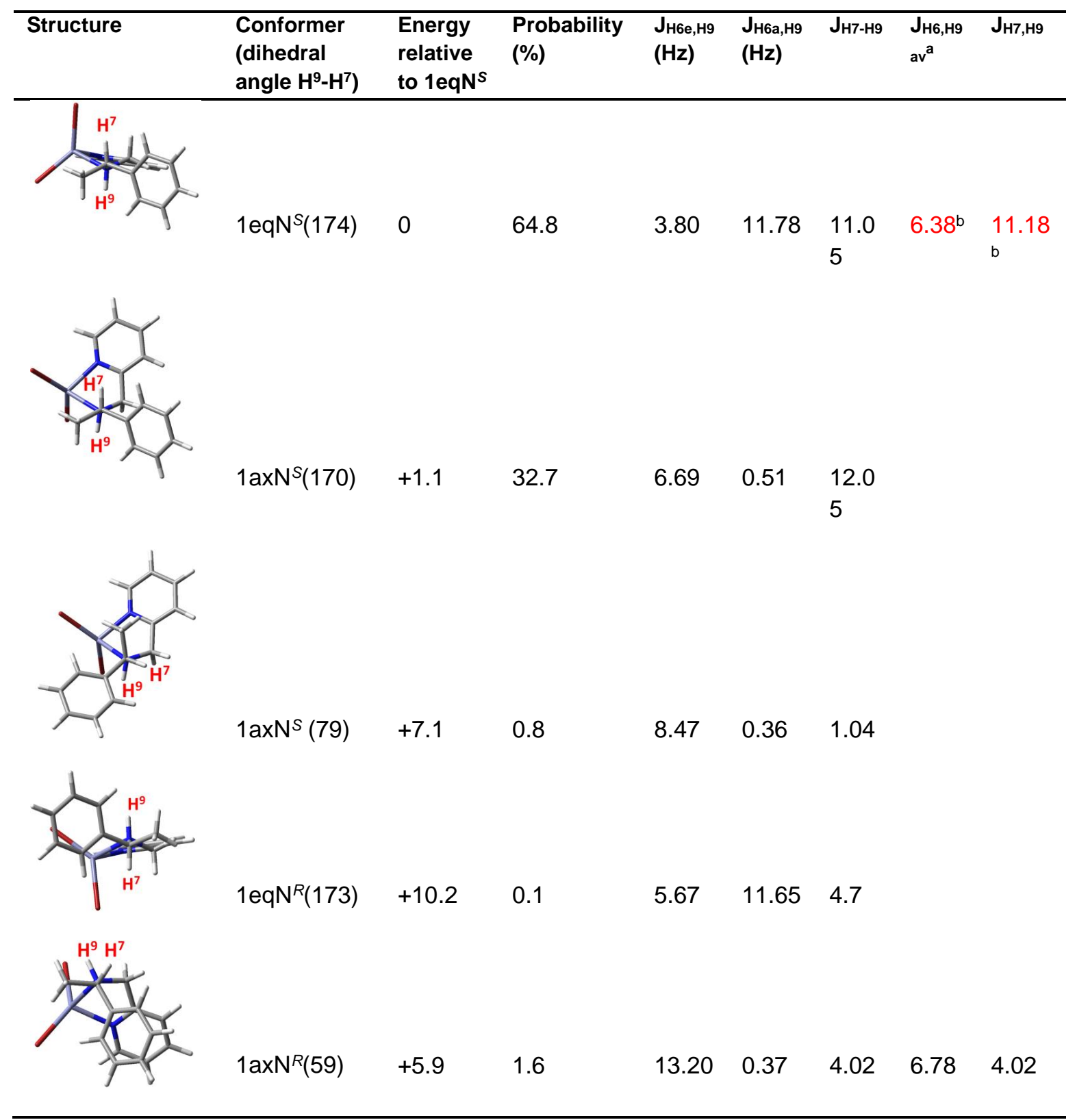

[a] averaged coupling: $\left(\mathrm{J}_{\mathrm{H} 6 \mathrm{e}, \mathrm{H} 9}+\mathrm{J}_{\mathrm{HGa}, \mathrm{H} 9}\right) / 2 .{ }^{[b]}$ conformationaly weighted calculated $\mathrm{J}_{\mathrm{H}, \mathrm{H}}$ according to probabilities

Among all lowest energy conformers for $1 \mathrm{eq} N^{R}, \operatorname{1ax} N^{R}, 1 e q N^{S}$ and $1 a x N^{S}$, the five lowest ones which exhibit a $\Delta \mathrm{E} \leq 10.2 \mathrm{KJ} / \mathrm{mol}$ relative to $1 \mathrm{eqN}^{S}$ have been considered. Their $3 \mathrm{D}$ structure, corresponding energies and dihedral angles between $\mathrm{H}^{9}-\mathrm{H}^{7}$ are gathered in table 1 , together with the corresponding Boltzmann probability and calculated $J_{\mathrm{H}, \mathrm{H}}$ thanks to the DFT/ Gauge Invariant Atomic Orbitals (GIAO) approach (ESI).

The $\mathrm{J}_{\mathrm{H}, \mathrm{H}}$ value between $\mathrm{H}^{6}$ and $\mathrm{H}^{9}$ in the $1 e q \mathrm{~N}^{S}$ conformer was calculated as a weighted average over 4 subsequent major contributors (see Table 1 and S1). This value of $6.4 \mathrm{~Hz}$ is 
close to the experimental one of $7.5 \mathrm{~Hz}$. In the same manner, $\mathrm{J}_{\mathrm{H} 7, \mathrm{H} 9}$ has been calculated at $11.2 \mathrm{~Hz}$ close to the $12.5 \mathrm{~Hz}$ value found experimentally. Same calculations for $1 \mathrm{eqN}^{R}$ and

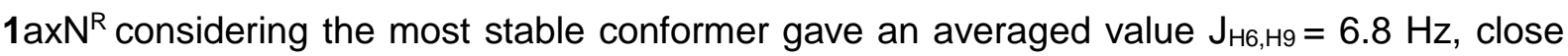
to the experimental one. However, the calculated $\mathrm{J}_{\mathrm{H} 7 \mathrm{H9}}=4.0 \mathrm{~Hz}$ is far from the measured value, confirming that this diastereoisomer is not formed in solution. A significant contribution of other conformers of higher energy remains unlikely.

Figure 6 shows the variation between calculated and experimental $J_{H, H}\left(J_{H 6, H 9}\right.$ and $\left.J_{H 7, H 9}\right)$ coupling constants for each conformer and evidences that 1 eq $N^{S}(174)$ and $1 \operatorname{axN}^{S}(170)$ are conformers with the highest contribution, due to their smallest calculated-versusexperimental differences.

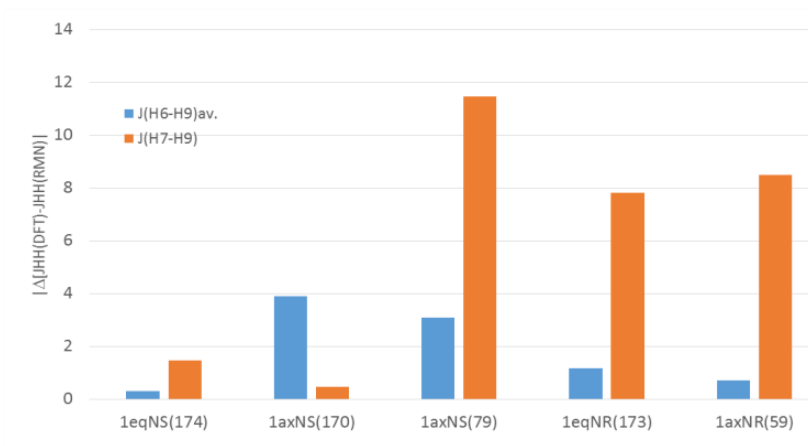

Figure 6. ${ }^{1} \mathrm{H}-{ }^{1} \mathrm{H}$ scalar coupling constant differences $\left[\Delta \mathrm{J}_{\mathrm{H}, \mathrm{H}}\right.$ DFT-NMR] between calculated (DFT) and experimental (NMR) approaches, respectively by GIAO single point calculations and GSERF experiments for the five most stable structures of complex 1.

The same approach was conducted for interatomic hydrogen distances $\left(\mathrm{d}_{\mathrm{H}, \mathrm{H}}\right)$ in complex 1: calculated values for the $1 \operatorname{eqN}^{S}(174), 1 a x N^{S}(170), 1 a x N^{S}(79)$ and $1 \operatorname{eqN}^{R}(173)$ structures have been compared to those obtained from NOESY experiments (Table 2 and ESI). Only the most relevant $d_{H, H}$ between flexible moieties were used to differentiate conformers and diastereoisomers: $\mathrm{H}^{7}-\mathrm{H}^{9}$ and $\mathrm{H}^{6}-\mathrm{H}^{10}$ allow distinguishing the most stable conformers: 1eq $N^{S}(174)$ and $1 \operatorname{axN}^{S}(170)$, since their $|d(D F T)-d(N M R)|$ lead to smaller values (Table 2).

This approach has also been used to determine the most stable diastereoisomer between $\mathrm{N}^{S} \mathrm{C}^{S}$ and $\mathrm{N}^{R} \mathrm{C}^{S}$. Again, the calculated / experimental differences $|\mathrm{d}(\mathrm{DFT})-\mathrm{d}(\mathrm{NMR})|$ allow confirming that the $\mathrm{N}^{S} \mathrm{C}^{S}$ diastereoisomer is more stable than the $\mathrm{N}^{R} \mathrm{C}^{S}$ one as energetically quantified by DFT (compare $1 \operatorname{eqN}^{S}(174)$ to $\operatorname{1axNR}(59)$, table 2). This joint experimental (NMR) and theoretical studies shows that $\mathrm{J}_{\mathrm{H}, \mathrm{H}}$ coupling constants and $\mathrm{d}_{\mathrm{H}, \mathrm{H}}$ are good structural markers to determine the most stable conformers as well as the preferred diastereoisomer formed upon complexation of pma to $\mathrm{Zn}^{\text {" }}$ cation 
Table 2. Absolute difference between DFT (QM) calculated and NMR derived distances $\left(\mathrm{d}_{\mathrm{H}, \mathrm{H}}\right)$ by using NOESY experiments for the four most stable contributors of complex 1 and for both possible diastereomers in the most stable conformation labelled $1 \mathrm{eqN}^{S}(174)$ and $\operatorname{1ax} N^{R}(59)$.

\begin{tabular}{cccccc}
\hline & 1eqNR(173) & 1eqNS(174) & 1axNS(79) & 1axNS(170) & 1axNR(59) \\
\hline H8-H7 & 0.0105 & 0 & 0.0172 & 0.0038 & 0.0132 \\
H6a-H6e & 0.0240 & 0.0209 & 0.0110 & 0.0110 & 0.0494 \\
H7-H10 & 0.0136 & 0.0136 & 0.0286 & 0.0136 & 0.0253 \\
H10-H8 & 0.3249 & 0.3282 & 0.3399 & 0.3209 & 0.3324 \\
H7-H6av & 0.4053 & $\mathbf{0 . 1 7 5 3}$ & 0.2423 & 0.3447 & $\mathbf{0 . 3 2 5 3}$ \\
H9-H6av & 0.6396 & 0.6279 & 0.9045 & 0.8995 & 0.6406 \\
H6av-H10 & 1.7976 & $\mathbf{0 . 6 7 9 6}$ & $\mathbf{1 . 8 6 3 7}$ & 0.6971 & $\mathbf{0 . 7 6 4 0}$ \\
H7-H9 & 0.6209 & $\mathbf{0 . 1 1 1 8}$ & $\mathbf{0 . 5 9 0 9}$ & 0.1009 & $\mathbf{0 . 7 0 9 3}$ \\
\hline
\end{tabular}

\subsection{Solid-state study}

X-Ray diffraction structure was used to confirm that the predominant structure of the zinc complex determined in solution does correspond to the one collected from the solid-state data. To do so, we were able to obtain single crystals suitable for X-ray analysis for each enantiomeric complex by slow diffusion of pentane into concentrated THF solution. Ortep plots of $\mathrm{ZnBr}_{2}$ complexes are shown in Figure 8 and selected bond lengths and angles that account for the 3D structure of complexes $\mathbf{1}$ and $\mathbf{2}$ are gathered in table 2. Both complexes are isomorphous with very similar cell parameters.

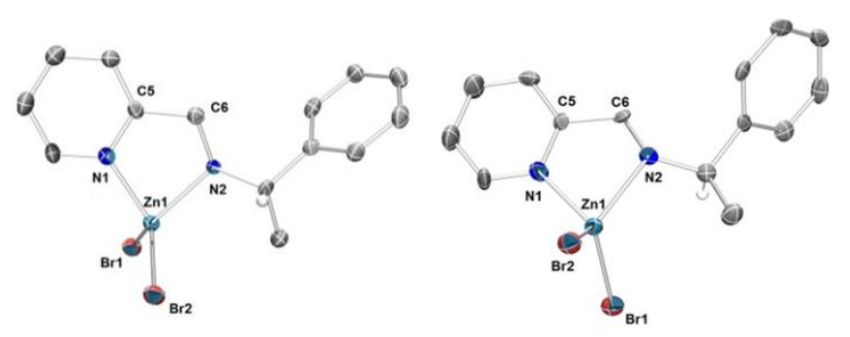

Figure 8. Ortep plots of $\mathbf{1}\left(\mathrm{L}^{S} \mathrm{ZnBr}_{2}\right.$, left $)$ and $\mathbf{2}\left(\mathrm{L}^{\mathrm{R}} \mathrm{ZnBr}_{2}\right.$, right) with $50 \%$ probability thermal ellipsoids. Most Hydrogen atoms were omitted for clarity.

They adopt a tetrahedral geometry due with no substantial difference in bond lengths and angles between 1 and $\mathbf{2}$ (Table 3). 
Table 3. Selection of bond lengths $(\AA)$ and angles $\left({ }^{\circ}\right)$ for complexes 1, 2 and already reported $\mathrm{L}^{\mathrm{S}} \mathrm{ZnCl} \mathrm{n}_{2}$ for comparison.

\begin{tabular}{|c|c|c|c|}
\hline & $1\left(\mathrm{LSZnBr}_{2}\right)$ & $2\left(\mathrm{~L}^{R} \mathrm{ZnBr}{ }_{2}\right)$ & $\mathrm{L}^{\mathrm{S} Z n C l}{ }_{2}{ }^{61}$ \\
\hline Zn1-N1 & $2.037(5)$ & $2.029(8)$ & $2.037(3)$ \\
\hline Zn1-N2 & $2.095(5)$ & $2.096(8)$ & $2.089(3)$ \\
\hline $\mathrm{Zn} 1-\mathrm{X} 1$ & $2.344(1)$ & $2.354(2)$ & $2.2025(12)$ \\
\hline $\mathrm{Zn} 1-\mathrm{X} 2$ & $2.351(1)$ & $2.344(1)$ & $2.2134(11)$ \\
\hline N1-C5 & $1.338(7)$ & $1.34(1)$ & $1.332(5)$ \\
\hline C5-C6 & $1.500(8)$ & $1.49(1)$ & $1.511(5)$ \\
\hline C6-N2 & $1.482(8)$ & $1.49(1)$ & $1.479(4)$ \\
\hline N1-Zn1-N2 & $83.7(2)$ & $83.6(3)$ & $83.58(12)$ \\
\hline N1-Zn1-X2 & 113.6(2) & $109.8(2)$ & $113.45(11)$ \\
\hline Br1-Zn1-X2 & $118.01(3)$ & $118.00(6)$ & $117.13(4)$ \\
\hline N2-Zn1-X1 & $109.1(2)$ & $117.7(2)$ & $109.70(9)$ \\
\hline Zn1-N1-C6-N2 & 12.30 & -12.85 & 13.09 \\
\hline H9n-N2-C7-H7 & -172.57 & 177.92 & -175.74 \\
\hline
\end{tabular}

These structures are very similar to that published for $\mathrm{L}^{\mathrm{S}} \mathrm{ZnCl}_{2}{ }^{61}$ the principal difference being the longer $\mathrm{Zn}-\mathrm{Br}$ bonds (2.34 $\AA$ ) compared to the $\mathrm{Zn}-\mathrm{Cl}$ ones (2.20 $\AA$ on average) which is explained by the size of the halides. Otherwise bond lengths and angles are very similar for the three structures (Table 3). It is noteworthy that for both 1 and 2 complexes, the benzylic fragment lies in equatorial position, as anticipated from the study in solution. In the same manner, the anti-conformation of the $\mathrm{H}^{7}$ and $\mathrm{H}^{9}$ hydrogen atoms was confirmed by this solidstate analysis (Figure 9).

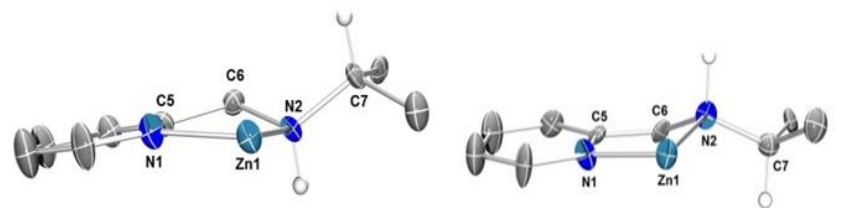

Figure 9. Side-view of 1 ( $\mathrm{L}^{\mathrm{S}} \mathrm{ZnBr}_{2}$, left) and $2\left(\mathrm{~L}^{\mathrm{R}} \mathrm{ZnBr}\right.$, right) using $50 \%$ probability thermal ellipsoids. Most Hydrogen atoms were omitted for clarity as well as bromines and five carbons of the phenyl ring.

Moreover, for these complexes the unit cell contains four molecules (space group P $2{ }_{1} 2_{1} 2_{1}$ ), and, as for the chloride complex, the only observed short contacts take place between hydrogens and bromines (see Figure S13). Our further objective was to gain informations on the overall $3 \mathrm{D}$ structure of Co complexes. We were especially interested in determining if the 
observed preferred diasteroisomer formation and conformation evidenced for zinc complexes would be the same with another metal.

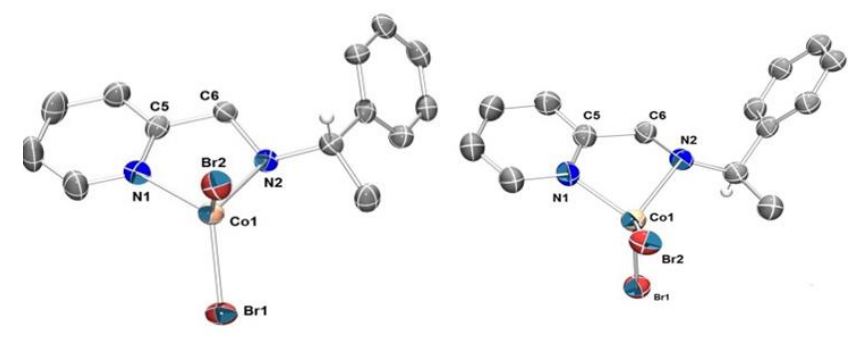

Figure 10. Ortep plots of $3\left(\mathrm{~L}^{S} \mathrm{CoBr}_{2}\right.$, left $)$ and $4\left(\mathrm{~L}^{R} \mathrm{CoBr}_{2}\right.$, right) $50 \%$ probability thermal ellipsoids. Most Hydrogen atoms were omitted for clarity.

The structure of cobalt complexes $\mathbf{3}$ and $\mathbf{4}$, for which NMR studies would be more difficult to conduct due to the paramagnetic relaxation effect of Co", were investigated in the solid-state (Figure 10).

Table 3. Selection of bond lengths $(\AA)$ and angles $\left(^{\circ}\right)$ for complexes 3, 4.

\begin{tabular}{lll}
\hline & $\mathbf{3}\left(\mathbf{L}^{\mathbf{S}} \mathrm{CoBr}_{2}\right)$ & $\mathbf{4}\left(\mathbf{L}^{R} \mathrm{CoBr}_{2}\right)$ \\
\hline Co1-N1 & $2.017(3)$ & $2.03(1)$ \\
Co1-N2 & $2.080(3)$ & $2.071(8)$ \\
Co1-Br1 & $2.3555(7)$ & $2.361(2)$ \\
Co1-Br2 & $2.3744(7)$ & $2.369(2)$ \\
N1-C5 & $1.340(5)$ & $1.32(1)$ \\
C5-C6 & $1.511(5)$ & $1.52(1)$ \\
C6-N2 & $1.485(5)$ & $1.47(1)$ \\
N1-Co1-N2 & $84.4(1)$ & $83.4(3)$ \\
N1-Co1-Br2 & $110.6(1)$ & $116.1(3)$ \\
Br1-Co1-Br2 & $118.01(3)$ & 116.17 \\
N2-Co1-Br1 & $109.1(2)$ & $112.2(2)$ \\
Co1-N1-C6-N2 & 12.78 & -19.92 \\
H9n-N2-C7-H7 & 174.4 & -173.94 \\
\hline
\end{tabular}

For those pma-cobalt complexes no previous X-ray structure was reported. The structure of 3 and $\mathbf{4}$ resemble those of the $\mathrm{Zn}$ compounds and are very similar to each other in terms of metrics and angles (Table 3). They crystallize in a non centrosymmetric chiral orthorombic space group $\left(P 2{ }_{1} 2_{1} 2_{1}\right)$, with cell parameters close to those of complexes $\mathbf{1}$ and 2 . As observed for the zinc complexes the conformation of the metallacycle changes with the 
stereochemistry of the methylene carbon. Noteworthy the torsion angle is in this case a little bit larger in absolute value for 4 bearing the $L^{R}$ ligand than for 3 . This induces a small widening of the $\mathrm{N}-\mathrm{Co}-\mathrm{Br}$ angle. As for $\mathbf{1}$ and 2 , the cell unit contains 4 molecules (space group $P 2{ }_{1} 2_{1} 2_{1}$ ) with most short contacts being observed between bromine and hydrogens.

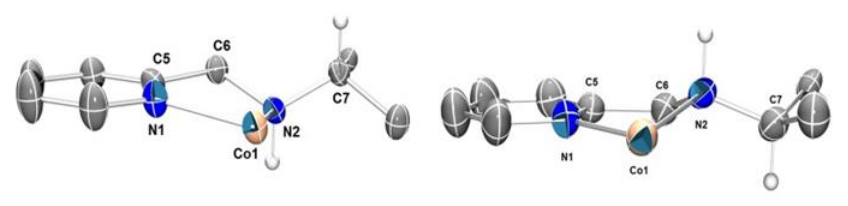

Figure 11. Side-view of $3\left(\mathrm{~L}^{\mathrm{S}} \mathrm{CoBr}\right.$, left $)$ and $4\left(\mathrm{~L}^{R} \mathrm{CoBr}_{2}\right.$, right $)$ using $50 \%$ probability thermal ellipsoids. Most Hydrogen atoms were omitted for clarity as well as bromines and five carbons of the phenyl ring.

The geometry of $\mathrm{Zn}$ and Co complexes markedly differs from the Pd" analogue due to the propensity of $\mathrm{Zn}$ and Co to form tetrahedral arrangements instead of square planar for the $\mathrm{Pd}$ counterpart. The corresponding $\mathrm{L}^{R} \mathrm{PdCl}_{2}$ as well as all pyridylmethylamine-based $\mathrm{Pd}$ complexes within this series displays a topology set by a strong $\square$-interaction between the pyridine and phenyl ring of the ligand (see ESI). ${ }^{20}$

In order to validate our DFT/NMR/X-ray approach, DFT/NMR and X-ray derived structures have been compared (see Figure 12.A). For the zinc complex 1, structures are close but not similar with some differences (RMS $=3.3 \AA$ ). These weak discrepancies are probably due to the effect of the solvent on the most stable conformer (in yellow Figure 12.A and table 1) as compared to the crystallographic structure (in purple Figure 12.A). This effect is also seen for the Co complex 3 showing a fit between structures of $3.4 \AA$ (Figure 12.C).

NMR data on complex 3 were difficult to interpret despite DFT/GIAO derived NMR data (not shown) due to the paramagnetic relaxation induced by the Co" metallic center. Alternatively, complex 3 could be crystallized and X-ray derived structures of complex 3 (in light blue Figure 12.B) are almost surprisingly similar to complex 1 (in purple Figure 12.B) as showed by the RMS $=1.66 \mathrm{~A}^{\circ}$. On the contrary, the DFT derived structures between $\mathrm{Zn}$ and Co are close but with small conformational differences especially in the $\mathrm{Br}$-Metal-Br angle and also for the $\mathrm{CH}(\mathrm{Me}) \mathrm{Ph}$ lateral chain position (Figure 12.D). A general tendency put into relief by the previous comparative study is the very close five membered ring metallacycle conformation with an equatorial substituent whatever the state of matter. Moreover, the 
lateral chain $\mathrm{CH}(\mathrm{Me}) \mathrm{Ph}$ show some slight conformational changes depending on the considered metal and the state of matter.
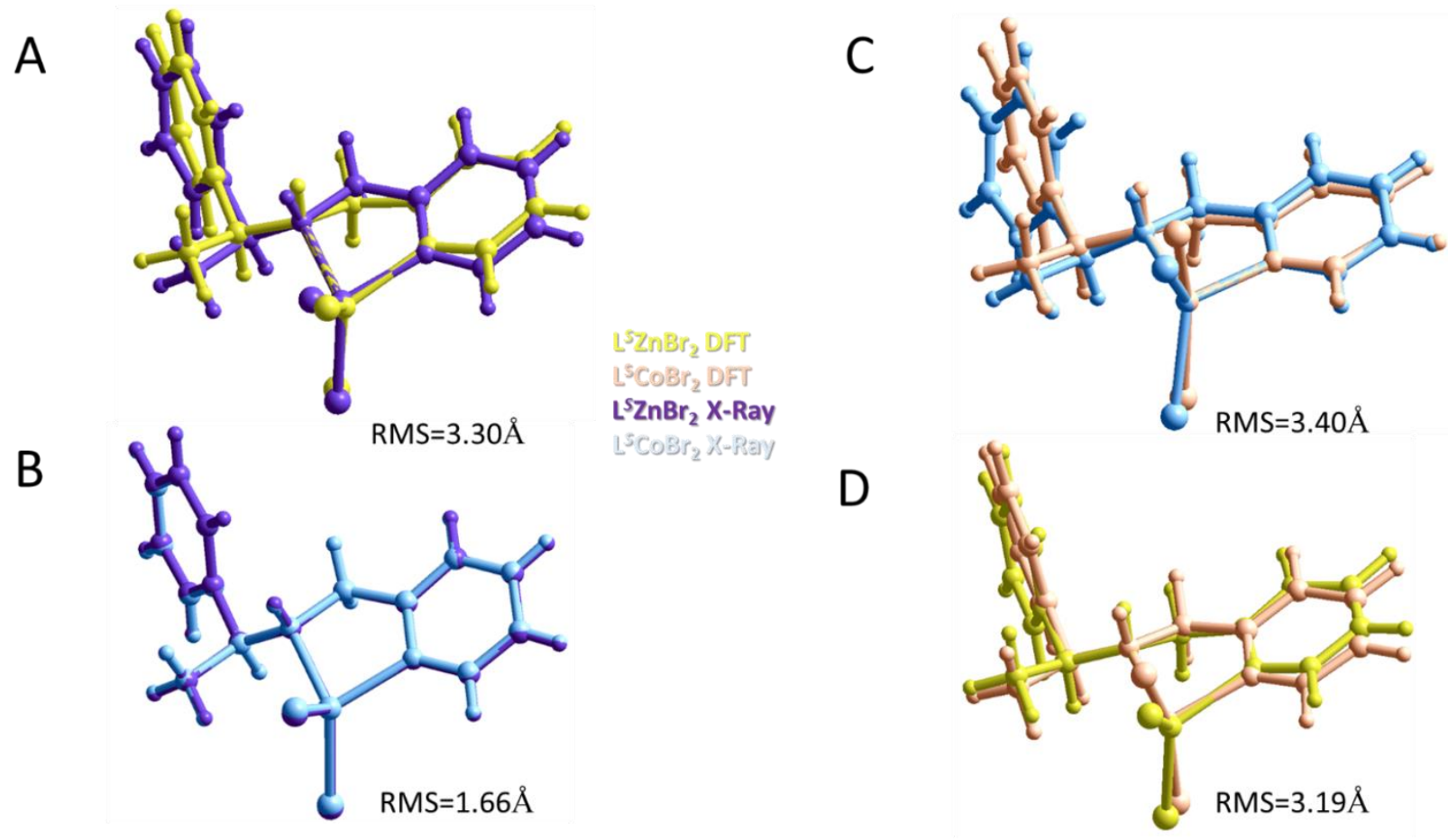

Figure 12. Overlay of A) X-ray (purple)/DFT (yellow) for complex 1, B) of X-ray data for complexes 1 (purple) and 3 (light blue), C) X-ray (light blue) and DFT (orange) data of complex 3 and D) DFT data comparison between complex 1 (yellow) and complex 3 (orange). RMS of different overlays are indicated as a comparison marker.

\section{Experimental Section}

\subsection{General procedures}

\subsubsection{Synthesis}

All non-aqueous reactions were carried out under an atmosphere of argon in flame- or ovendried glassware with magnetic stirring. All reagents and solvents obtained from commercial sources were used without further purification unless otherwise noted. $\mathrm{CH}_{2} \mathrm{Cl}_{2}$ was distilled over $\mathrm{CaH}_{2}$ before use. Anhydrous THF and $\mathrm{Et}_{2} \mathrm{O}$ were used after distillation over sodium metal. Thin layer chromatography (TLC) was performed on silica gel $60 \mathrm{~F}_{254}$ and the plates were visualized with UV light $(254 \mathrm{~nm}$ ) or a potassium permanganate solution (1 $\mathrm{g}$ with $2 \mathrm{~g}$ of $\mathrm{K}_{2} \mathrm{CO}_{3}$ in $200 \mathrm{~mL}$ of water). The crude products were purified by preparative thin layer 
chromatography on silica gel $60 \mathrm{PF}_{254}$ or by column chromatography using silica gel Merck 60. Known compound structures were assigned by comparison with the literature spectroscopic data.

\subsubsection{NMR}

Routine ${ }^{1} \mathrm{H}$ and ${ }^{13} \mathrm{C}$ NMR spectra were recorded on a Bruker AM 360, AM 300, DPX 200 and DPX 250 spectrometers at room temperature; Chemical shifts for ${ }^{1} \mathrm{H}$ and ${ }^{13} \mathrm{C}$ were referenced internally according to the residual solvent resonances and reported in ppm relative to $\mathrm{CDCl}_{3}$ or $\left(\mathrm{CD}_{3}\right)_{2} \mathrm{CO}$. All coupling constants ( $J$ values) are given in hertz $(\mathrm{Hz})$. Data appear in the following order: chemical shift in ppm, multiplicity ( $s$, singlet; $d$, doublet; $t$, triplet; q, quadruplet; $m$, multiplet), coupling constant $J$, number of protons, and assignment.

Advanced NMR spectra were performed at 9.4 T on a Bruker DRX 400 spectrometer using a ${ }^{1} \mathrm{H} /{ }^{13} \mathrm{C} / \mathrm{X}$ Triple Broad Band Inverse probe equipped with a $\mathrm{z}$ field gradient coil and a standard variable- temperature unit (BVT 3000). All experiments carried out at low temperature $(193 \mathrm{~K})$, were prepared using $\left(\mathrm{CD}_{3}\right)_{2} \mathrm{CO}$ as solvent. All 3D GSERF spectra were obtained by recording $4096 \times 32 \times 24$ matrices converted by the pure shift macro ${ }^{62,63}$ to $2 \mathrm{D}$ 4096 × 32 points in the F1 dimension. No apodization was applied in each dimension prior the double Fourier transform. Phased 2D maps were obtained using the Quadrature Sequential Mode.

For the zinc complex, a $40 \mathrm{~ms}(400 \mathrm{~Hz})$ Burp pulses (EBURP-2 for excitation, REBURP for refocusing and a time reversal EBURP-2 for flip back) have been used in the SERF block for selecting ${ }^{1} \mathrm{H}$ areas. In the band selective ${ }^{1} \mathrm{H}-{ }^{1} \mathrm{H}$ decoupled spectra a $\mathrm{RSNOB}{ }^{64}$ selective pulse of $40 \mathrm{~ms}$ duration and bandwidth of $65 \mathrm{~Hz}$. The homodecoupled spectra were acquired with number of $\mathrm{t} 2$ increments (i.e., number of FID chunks) equal to 32 , the duration of FID chunk is $19.2 \mathrm{~ms}$, the number of complex data points of constructed FID in $1 \mathrm{H}$ dimension is 4096, the recycling delay is $1 \mathrm{~s}$, and the number of scans is 4 .

${ }^{1} \mathrm{H}-{ }^{1} \mathrm{H}$ exchange spectroscopy (NOESY) is routinely used to access dynamic processes within a particular time-scale window. Series of 2D spectra are acquired with different mixing times $t_{\text {mix }}$ to generate build-up curves associated with NOEs that produce variations of diagonal-to-cross-peak volume ratios. Buildup curves comprising signal intensity dependence of the cross- and diagonal- peaks with the mixing time $\left(\mathrm{t}_{\text {mix }}\right)$ was fitted according to the calculation detailed in the Supporting Information. ${ }^{46}$ 


\subsubsection{X-Ray}

X-ray crystallography data were collected at $150 \mathrm{~K}$ on a Bruker Kappa APEX II diffractometer using a Mo-k $(\lambda=0.71069 \AA) X$-ray source and a graphite monochromator. The crystal structures were solved using SIR $97^{64}$ or Shelxt ${ }^{65}$ and refined using Shelxl-97 ${ }^{66}$ or Shelxl-2013. ORTEP drawings were made using ORTEP III ${ }^{67}$ for Windows or Mercury.

\subsection{Experimental procedures}

\subsubsection{Reductive amination.}

To a stirred solution of amine ( 1 eq) and $\mathrm{MgSO}_{4}(2 \mathrm{eq})$, dichloromethane or THF ( $1 \mathrm{~mL}$ per $0.1 \mathrm{mmol}$ ) was added the carboxaldehyde derivative (1 eq). The mixture is stirred at room temperature for $2 \mathrm{~h}$. After filtration and concentrated under vacuum, $\mathrm{MeOH}(1 \mathrm{~mL}$ per 0.1 mmol) and $\mathrm{NaBH}_{4}$ (3eq) were added. The reaction mixture was stirred at room temperature for $2 \mathrm{~h}$. The solution was then concentrated under vacuum and $10 \mathrm{~mL}$ of saturated aqueous solution of $\mathrm{NH}_{4} \mathrm{Cl}$ was added, the aqueous phase was extracted with EtOAc ( $\left.3 \times 10 \mathrm{~mL}\right)$. The combined layers were dried $\left(\mathrm{MgSO}_{4}\right)$, filtered and concentrated under vacuum. The crude product was purified by flash chromatography on silica gel.

\subsubsection{Complexation to $\mathrm{MBr}_{2}$}

$\mathrm{MBr}_{2}(0.70 \mathrm{mmol})$ is added to a solution of $\mathbf{L}^{S}$ or $\mathbf{L}^{R}(155 \mathrm{mg}, 0.73 \mathrm{mmol})$ in THF $(4 \mathrm{~mL})$. The solution is stirred for $24 \mathrm{~h}$ at room temperature. The reaction mixture is concentrated under vaccum. The solid residue is next suspended in $\mathrm{Et}_{2} \mathrm{O}(10 \mathrm{ml})$ and filtrated. The solid is washed three times with $\mathrm{Et}_{2} \mathrm{O}(10 \mathrm{ml})$ and dried under vacuum to yield the expected complex $1,2,3$ or 4 .

\subsection{3. $N-[(S)-1-p h e n y l e t h y l]-N-[1-(2-p y r i d i n y l) m e t h y l] a m i n e ~ L^{S}$}

The crude product was purified by flash chromatography on silica gel with pentane/AcOEt $(75 / 25)$ as the eluent. Yield : quant. Yellow oil.

NMR ${ }^{1} \mathrm{H}:\left(400 \mathrm{MHz},\left(\mathrm{CD}_{3}\right)_{2} \mathrm{CO}\right), \delta(\mathrm{ppm}), J(\mathrm{~Hz}): 1.31(\mathrm{~d}, J=7.5,3 \mathrm{H}) ; 3.61(\mathrm{~s}, 2 \mathrm{H}) ; 3.77$ (q, $J=$ 6, 1H); $7.26(\mathrm{~m}, 2 \mathrm{H}) ; 7.35(\mathrm{t}, J=7,2 \mathrm{H}) ; 7.44(\mathrm{~m}, J=7.3,3 \mathrm{H}) ; 7.76(\mathrm{td}, J=7.7,1.7,1 \mathrm{H}) ; 8.5$ (d, $J=4,1 \mathrm{H}) . \mathrm{NMR}^{1} \mathrm{H}:\left(200 \mathrm{MHz}, \mathrm{CDCl}_{3}\right), \delta(\mathrm{ppm}), J(\mathrm{~Hz}): 1.42(\mathrm{~d}, J=6.5,3 \mathrm{H}) ; 2.65$ (brs, 
1H); 3.75(s, 2H); 3.83 (q, J = 6.5, 1H); 7.09-7.41 (m, 7H); 7.59 (td, $J=7.6,1.7,1 \mathrm{H}) ; 8.55$ (d, $J=4.7,1 \mathrm{H}) . \mathrm{NMR}{ }^{13} \mathrm{C}:\left(75 \mathrm{MHz}, \mathrm{CDCl}_{3}\right), \delta(\mathrm{ppm}): 23.83 ; 52.45 ; 57.42 ; 121.23 ; 121.82$; $126.18 ; 126.57 ; 127.87 ; 135.71 ; 144.77 ; 148.67 ; 159.20$. HRMS: calculated for C14H17N2 $[\mathrm{M}+\mathrm{H}+]=213.1392 ;$ found: 213.1388 . Data in accordance with literature. ${ }^{68}$

\subsection{4. $N$-[(R)-1-phenylethyl]-N-[1-(2-pyridinyl)methyl]amine $L^{R}$}

The crude product was purified by flash chromatography on silica gel with pentane/AcOEt $(75 / 25)$ as the eluent. Yield : quant. Yellow oil.

NMR ${ }^{1} \mathrm{H}:\left(200 \mathrm{MHz}, \mathrm{CDCl}_{3}\right), \delta(\mathrm{ppm}), J(\mathrm{~Hz}): 1.36$ (d, $\left.J=6.5,3 \mathrm{H}\right) ; 2.35$ (brs, $\left.1 \mathrm{H}\right) ; 3.7$ (s, 2H); $3.78(\mathrm{q}, J=6.6,1 \mathrm{H}) ; 6.99-7.36(\mathrm{~m}, 7 \mathrm{H}) ; 7.47(\mathrm{td}, J=7.6,1.7,1 \mathrm{H}) ; 8.49(\mathrm{~d}, J=4.5,1 \mathrm{H})$. NMR ${ }^{13} \mathrm{C}:\left(75 \mathrm{MHz}, \mathrm{CDCl}_{3}\right), \delta(\mathrm{ppm}): 23.77 ; 52.37 ; 57.33 ; 121.13 ; 121.70 ; 126.10 ; 126.28 ; 127.78$; 135.59; 144.69; 148.57; 159.10. HRMS: calculated for $\mathrm{C} 14 \mathrm{H} 17 \mathrm{~N} 2[\mathrm{M}+\mathrm{H}+]=213.1392$; found: 213.1399 . Data in accordance with literature. ${ }^{55}$

4.2.5. Complex 1 (Yield : 58\%. White solid) / Complex 2 (Yield : 79\%. White solid) NMR ${ }^{1} \mathrm{H}$ : (400 MHz, $\left.\left(\mathrm{CD}_{3}\right)_{2} \mathrm{CO}\right), \delta(\mathrm{ppm}), J(\mathrm{~Hz}): 1.62(\mathrm{~d}, J=6.1,3 \mathrm{H}) ; 3.85(\mathrm{~m}, 2 \mathrm{H}) ; 4.17(\mathrm{q}, J=6,1 \mathrm{H})$; $5.25(\mathrm{~m}, 1 \mathrm{H}) ; 7.43(\mathrm{t}, J=7,1 \mathrm{H}) ; 7.51$ (t, $J=7.3,2 \mathrm{H}) ; 7.63(\mathrm{~d}, J=7.3,2 \mathrm{H}) ; 7.72(\mathrm{~d}, J=7.9$, $1 \mathrm{H}) ; 7.78(\mathrm{t}, J=6,1 \mathrm{H}) ; 8.22(\mathrm{t}, J=7.4,1 \mathrm{H}) ; 8.63(\mathrm{~d}, J=4.8,1 \mathrm{H}) . \mathrm{NMR}{ }^{13} \mathrm{C}:(100 \mathrm{MHz}$, $\left.\left(\mathrm{CD}_{3}\right)_{2} \mathrm{CO}\right), \delta(\mathrm{ppm}): 24.21 ; 51.69 ; 60.34 ; 124.76 ; 125.87 ; 127.98 ; 129.00 ; 130.89 ; 141.95$; 147.98; 156.82. HRMS: calculated for $\mathrm{C} 14 \mathrm{H} 16 \mathrm{~N} 2 \mathrm{Br} 2 \mathrm{ZnNa}[\mathrm{M}+\mathrm{Na}+]=456.8869$; found: 456.8875 .

4.2.6. Complex 3 (Yield : 70\%. Blue solid) / Complex 4 (Yield : 77\%. Blue solid) HRMS: calculated for $\mathrm{C} 14 \mathrm{H} 16 \mathrm{~N} 2 \mathrm{BrCo}[\mathrm{M}+-\mathrm{Br}]=349.9823$; found: 349.9824 .

\section{Conclusions}

This solid-state study of $\mathrm{Zn}$ - and Co-complexes evidenced some key features regarding the conformation of the metallacycle, the configuration of the $\mathrm{sp}^{3}$ nitrogen atom set during the complexation process, the pseudo equatorial position of the benzyl side arm as well as the preferred spatial arrangement of the chiral side arm with respect to the metallacycle. It perfectly fits with the structures of $\mathbf{1}$ and $\mathbf{2}$ evidenced in solution thanks to an NMR study complemented for 1 by DFT calculations. The combination of various structural elucidation methods like DFT/NMR in solution and X-Ray in solid state is the key to better understand complex stability regarding its potential reactivity. Comparing different sources of structural 
data is the only one way to make a given approach more robust for investigating unknown complexations. In particular, for Zn-pma complex, NMR/DFT approach remains a great alternative for deciphering the ligand folding around the metal when the resulting complex could not diffract and /or be crystallized.

\section{Acknowledgements}

The authors acknowledge the MENRS, CNRS, Ecole Polytechnique, Universities of Versailles Saint-Quentin-en-Yvelines, Paris-Saclay, as part of the "Investissements d'Avenir" program (ANR-11-IDEX-0003-02), and CHARMMMAT labex (ANR-11-LABEX-0039) for funding to J.E.H.P. J.F. thanks his partner Sandrine Bouchet for unfailing assistance. Louis Ricard and Sophie Bourcier are deeply thanked for discussion on X-ray structures and HRMS analysis.

\section{Appendix A. Supplementary data}

\section{References}

[1] M. Kruppa, B. König, Chem. Rev. 106 (2006) 3520-3560.

[2] D. Chandra, T. Ohji, K. Kato, T. Kimura, Langmuir 27 (2011) 11436-11443.

[3] A. Congreve, R. Kataky, M. Knell, D. Parker, H. Puschmann, K. Senanayake, L. Wylie, New J. Chem. 27( 2003) 98-106.

[4] C. Hemmert, M. Renz, H. Gornitzka, B. Meunier, J. Chem. Soc., Dalton Trans. (1999) 3989-3994.

[5] J. M. Rowland, M. M. Olmstead, P. K. Mascharak, Inorg. Chem. 39 (2000) 53265332.

[6] J. Chang, S. Plummer, E. S. F. Berman, D. Striplin, D.; Blauch, Inorg. Chem. 43, (2004) 1735-1742.

[7] M. Van den Heuvel, T. A. Van den Berg, R. M. Kellogg, C. T. Choma, B. L. Feringa, J. Org. Chem. 69 (2004) 250-262.

[8] T. Wang, X-Q. Hao, X.-X. Zhang, J.-F. Gong, M.-P. Song, Dalton Trans. 40 (2011) 8964-8976.

[9] C. Hemmert, M. Renz, H. Gornitzka, S. Soulet, B. Meunier, Chem. Eur. J. 5 (1999) 1766-1774.

[10] W. Baratta, G. Chelucci, S. Gladiali, K. Siega, M. Toniutti, M. Zanette, E. Zangrando, P. Rigo, Angew. Chem., Int. Ed. 44 (2005) 6214-6219. 
[11] S. Marque, V. Razafimahaléo, A. Dinut, G. Grach, D. Prim, X. Moreau, R. Gil, New J. Chem. 37 (2013) 2683-2690.

[12] K. Suzuki, P. D. Oldenburg, L. Que, Jr., Angew. Chem. Int. Ed. 47 (2008) 1887-1889.

[13] L. Zhang, Z. Zuo, X. Wan, Z. Huang, J. Am. Chem. Soc. 136 (2014) 15501-15504.

[14] P. Nareddy, L. Mantilli, L. Guénée, C. Mazet, Angew. Chem., Int. Ed. 51 (2012) 3826-3831.

[15] J. Chen, T. Xi, Z. Lu, Org. Lett. 2014, 16, 6452-6455.

[16] C. Nájera, J. Gil-Moltó, S. Karlström, L. R. Falvello, Org. Lett. 5 (2003) 1451-1454.

[17] H. Brunner, M. Schimdt, H. Schönenberger, Inorg. Chimica Acta 123 (1986) 201-207.

[18] W. J. Kerr, M. Middleditch, A. J. B. Watson, Synlett (2011) 177-180.

[19] A. Requet, O. Colin, F. Bourdreux, S. M. Salim, S. Marque, C. Thomassigny, C. Greck, J. Farjon, D. Prim, Magn. Res. Chem. 52 (2014) 273-278.

[20] G. Grach, G. Pieters, A. Dinut, V. Terrasson, R. Medimagh, A. Bridoux, V. Razafimahaleo, A. Gaucher, S. Marque, J. Marrot, D. Prim, R. Gil, J. Giner Planas, C. Vinas, I. Thomas, J.-P. Roblin, Y. Troin, Organometallics 30 (2011) 4074-4086.

[21] V. Terrasson, J. Giner Planas, C. Vinas, F. Teixidor, D. Prim, M. E. Light, M. B. Hursthouse, Organometallics 29 (2010) 4130-4134.

[22] O. Colin, H. Boufroura, C. Thomassigny, S. Perato, A. Gaucher, J. Marrot, D. Prim, Eur. J. Org. Chem. (2017)746-752.

[23] A. Aillerie, V. Rodriguez-Ruiz, R. Carlino, F. Bourdreux, R. Guillot, S. BezzenineLafollée, R. Gil, D. Prim, J. Hannedouche, ChemCatChem. 8 (2016) 2455-2460.

[24] S. Perato, B. Large, Q. Lu, A. Gaucher, D. Prim, ChemCatChem. 9 (2017) 389-392.

[25] M. Westerhausen, T. Bollwein, N. Makropoulos, S. Schneiderbauer, M. Suter, H. Nöth, P. Mayer, H. Piotrowski, K. Polborn, A. Pfitzner, Eur. J. Inorg. Chem. (2002) 389-404.

[26] F. A. Scaramuzzo, E. Badetti, G. Licini, C. Zonta, Eur. J. Org. Chem. (2017) 14381442.

[27] L. A. Joyce, M. S. Maynor, J. M. Dragna, G. M. da Cruz, V. M. Lynch, J. W. Canary, E. V. Anslyn, J. Am. Chem. Soc. 133 (2011) 13746-13752.

[28] S. Nayab, H. Lee, J. H. Jeong, Polyhedron 43 (2012) 55-62.

[29] C. K. Williams, L. E. Breyfogle, S. K. Choi, W. Nam, V. G. Young, Jr., M. A. Hillmyer, W. B. Tolman, J. Am. Chem. Soc. 125 (2003) 11350-11359.

[30] M. P. Cuajungco, G. J. Lees, R. R. Kydd, R. E. Tanzi, A. I. Bush, Nutr. Neurosci. 2 (1999)191-208.

[31] S. W. Suh, K. B. Jensen, M. S. Jensen, D. S. Silva, P. J. Kesslak, G. Danscher, C. J. Frederickson, Brain Res. 852 (2000) 274-278.

[32] X. Huang, M. P. Cuajungco, C. S. Atwood, R. D. Moir, R. E. Tanzi, A. I. Bush, J. Nutr. 130 (2000) 1488S-1492S. 
[33] E. Andrasi, E. Farkas, D. Gawlik, U. Rosick, P.Bratter, J. Alzheimer's Disease 2 (2000)17-26.

[34] D. W. Choi, J. Y. Koh, Annu. Rev. Neurosci. 21 (1998) 347-375.

[35] L. M. T. Canzoniero, D. M. Turetsky, D. W. Choi, J. Neurosci. 19 (1999) RC31.

[36] J. H. Weiss, S. L. Sensi, J. Y. Koh, Trends Pharm. Sci. 21 (2000) 395-401.

[37] Y.-K. Song, S. K. Kang, Y.-I. Kim, Bull. Korean Chem. Soc. 36 (2015) 374-377.

[38] M.; Royzen, J. W. Canary, Polyhedron 58 (2013) 85-91.

[39] Z. Dai, X. Xu, J. W. Canary, Chem. Commun. (2002) 1414-1415.

[40] Z. Dai, J. W. Canary, New J. Chem. 31 (2007) 1708-1718.

[41] J. Liang, J. W. Canary, Chirality 23 (2011) 24-33.

[42] Y.-H. Chiu, G. J. Gabriel, J. W. Canary, Inorg. Chem. 44 (2005) 40-44.

[43] B. L. Vallee, D. S. Auld, Acc. Chem. Res. 26 (1993) 543-551.

[44] Y. Yang, Y. Hayashi, Y. Fujii, T. Nagano, Y. Kita, T. Ohshima, J. Okuda, K. Mashima, Catal. Sci. Technol. 2 (2012) 509-513.

[45] S.-S. Wu, X.-W. Zhang, W.-L. Dai, S.-F. Yin, W.-S. Li, W.-Q. Ren, C.-T. Au, Appl. Catal. A 341 (2008) 106-111.

[46] J. E. H. Pucheta, J.-M. Gillet, D. Prim, J. Farjon, ChemPhysChem 17 (2016) 10341045.

[47] M. Westerhausen, T. Bollwein, K. Polborn, Z. Naturforsch. 55b (2000) 51-59.

[48] S. M. Ujwaldev, N. A. Harry, M. A. Divakar, G. Anilkumar, Catal. Sci. Technol. 8 (2018) 5983-6018.

[49] A. Mukherjee, D. Milstein,. ACS Catalysis 8 (2018) 11435-11469.

[50] M. Moselage, J. Li, L. Ackermann, ACS Catalysis 6 (2016) 498-525.

[51] C. E. I. Knappke, S. Grupe, D. Gärtner, M. Corpet, C. Gosmini, A. J. von Wangelin, Chem. Eur. J. 20 (2014) 6828-6842.

[52] G. Cahiez, A. Moyeux, Chem. Rev. 110 (2010) 1435-1462.

[53] A. Requet, H. Yalgin, D. Prim, Tetrahedron Lett. 56 (2015) 1378-1382.

[54] V. Terrasson, D. Prim, J. Marrot, Eur. J. Inorg. Chem. (2008) 2739-2745.

[55] G. Grach, A. Dinut, S. Marque, J. Marrot, R. Gil, D. Prim, Org. Biomol. Chem. 9 (2011) 497-503.

[56] N. Giraud, L. Beguin, J. Courtieu, D. Merlet, Angew. Chem. Int. Ed. 49 (2010) 34813484.

[57] $193 \mathrm{~K}$ was found optimum temperature in order to investigate spatial arrangement. At room temperature, signal broadening prevent the probing of spatial arrangement, but is acceptable for structural elucidation. 
[58] J. E. H. Pucheta, M. Candy, O. Colin, A. Requet, F. Bourdreux, E. Galmiche-Loire, A. Gaucher, C. Thomassigny, D. Prim, M. Mahfoudh, E. Leclerc, J.-M. Campagne, J. Farjon, Phys. Chem. Chem. Phys. 17 (2015) 8740-8749.

[59] J. A. Aguilar, S. Faulkner, M. Nilsson, G. A. Morris, Angew. Chem. Int. Ed. 49 (2010) 3901-3903.

[60] Similar computed details can be found in the ESI for enantiomeric ligand $L^{R}$ and complex 2. In this case, calculations point, similarly to the $L^{S / 1}$ couple, towards the preferential formation of one complex which geometry combines the preferred equatorial position of the benzyl side arm, the preferred conformation of the benzylic substituent and the $R$ configuration of the $\mathrm{sp}^{3}$ nitrogen atom.

[61] Q. T. Nguyen, J. H. Jeong, Acta Crystallogr. E 64 (2008) m457.

[62] http://nmr.chemistry.manchester.ac.uk/?q=node/256

[63] E. Kupče, J. Boyd and I. D. Campbell, J. Magn. Reson. Ser. B, 106 (1995) 300-303.

[64] A. Altomare, M. C. Burla, M. Camalli, G. L. Cascarano, C. Giacovazzo, A. Guagliardi, A. G. G. Moliterni, G. Polidori, R. Spagna, Journal of Applied Crystallography 32 (1999) 115119.

[65] G. M. Sheldrick, Acta Cryst. A, 71 (2015) 3-8.

[66] G. M. Sheldrick, SHELXL-97, Universität Göttingen, Göttingen, Germany, 1997.

[67] L. J. Farrugia, ORTEP-3 program, (2001) Department of Chemistry, University of Glasgow.

[68] W. Goldeman, B. Boduszek, Phosphorus, Sulfur, and Silicon and the Related Elements, 184 (2009) 1413-1425. 